\title{
Pathogen destruction versus intracellular survival: the role of lipids as phagosomal fate determinants
}

\author{
Benjamin E. Steinberg ${ }^{1,2}$ and Sergio Grinstein ${ }^{1,3}$
}

\author{
${ }^{1}$ Program in Cell Biology, Hospital for Sick Children, Toronto, Ontario, Canada. ${ }^{2}$ nstitute of Medical Science and \\ ${ }^{3}$ Department of Biochemistry, University of Toronto, Toronto, Ontario, Canada.
}

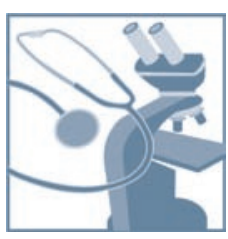

\begin{abstract}
Phagocytosis is a key component of the innate immune response and of the clearance of apoptotic bodies. Phagosome formation and subsequent maturation require extensive cytoskeletal rearrangement and precisely choreographed vesicular fusion and fission events. The objectives of this review are to highlight the functional importance of lipids in the phagocytic process, to discuss how pathogenic microorganisms can in some cases manipulate host lipid metabolism to either co-opt or disrupt phagosome maturation and promote their own survival, and to describe how defective phagosomal lipid metabolism can result in disease.
\end{abstract}

\section{Introduction}

Specialized cells of the immune system, such as macrophages and neutrophils, engage and actively engulf invading microorganisms into an intracellular vacuole by a process termed phagocytosis $(1,2)$. Inside this vacuole, also known as a phagosome, the invading organisms are killed and degraded by an array of microbicidal and digestive mechanisms. Therefore, phagocytosis represents a vital component of the innate immune response. In addition, because it is triggered by surface receptors that elicit an exquisitely orchestrated series of cytoskeletal and membrane remodeling events, phagocytosis can also be regarded as a particularly useful paradigm to investigate signal transduction.

Phagocytosis can be conceptually broken down into two modules: the formation of the nascent vacuole containing the ingested particle (phagosome formation), and its subsequent evolution into a degradative compartment (phagosome maturation) (Figure 1). Maturation is required because the nascent phagosome is not effectively microbicidal: its contents are a sampling of the innocuous extracellular milieu and its membrane is derived from the plasmalemma. Consequently, the phagosomal membrane and luminal contents must undergo considerable remodeling to transform the initially inert environment into a microbicidal one. This maturation process not only helps quell infection, but also generates and routes antigens for presentation on MHC molecules in order to activate the adaptive branch of the immune system (3).

Phagosome maturation is generally considered to involve primarily a complex sequence of fusion and fission events with subcompartments of the endocytic pathway (Figure 1). In many ways, phagosome maturation recapitulates the progression of cargo along the endocytic pathway, with the added advantage that the size of the vacuole enables detailed and unambiguous tracking of

Nonstandard abbreviations used: DAG, diacylglycerol; EEA1, early endosome antigen 1; LBPA, lysobisphosphatidic acid; MARCKS, myristoylated alanine-rich C-kinase substrate; PA, phosphatidic acid; PC, phosphatidylcholine; PH, pleckstrin homology; PI, phosphatidylinositol; PI(3)P, PI-3-phosphate; PI(4)P, PI-4-phosphate; $\mathrm{PI}(3,4,5) \mathrm{P}_{3}$, PI-3,4,5-trisphosphate; $\mathrm{PI}(3,5) \mathrm{P}_{2}$, PI 3,5-bisphosphate; $\mathrm{PI}(4,5) \mathrm{P}_{2}$, PI-4,5-bisphosphate; PIKfyve, FYVE finger-containing phosphoinositide kinase; PIP5KI, PI(4)P 5-kinase; PS, phosphatidylserine; PX, Phox homology; WASP, Wiskott-Aldrich Syndrome protein. Conflict of interest: The authors have declared that no conflict of interest exists. Citation for this article: J. Clin. Invest. 118:2002-2011 (2008). doi:10.1172/JCI35433. the maturing compartment by light microscopy. During and/or immediately after phagosome closure, the phagosome fuses with early endosomes, acquiring Rab5 and early endosome antigen 1 (EEA1) (1). Through fission events and subsequent interactions with late endosomes, the phagosome divests itself of the early endosomal markers and acquires a late endosome-like phenotype. Late phagosomes are positive for lysobisphosphatidic acid (LBPA), Rab7, and lysosome-associated membrane proteins (LAMPs). Ultimately, the organelles fuse with lysosomes to form phagolysosomes. These phagolysosomes represent the decisive degradative compartment, having amassed a potent antimicrobial repository consisting of hydrolytic enzymes, cationic peptides, and a markedly acidic luminal fluid (1). In the course of maturation, a powerful oxidative system composed of the NADPH oxidase and ancillary enzymes is also activated.

With the advent of proteomic and small, interfering RNA techniques, hundreds of proteins have been linked to the processes of phagosome formation and maturation (4-6). In contrast, much less attention has been paid to lipids as co-directors of phagocytosis. The past few years, however, have witnessed a remarkable resurgence in the study of lipids in the phagocytic event. The renewed interest in these historically neglected partners has been fueled in part by the development of genetically encoded biosensors to monitor lipid dynamics in live cells (7). Such sensors are generally chimeric constructs composed of a fluorescent protein in tandem with a domain that recognizes defined lipid headgroups. This and other strategies have produced evidence that lipids coordinate signaling, targeting, and trafficking events in the course of phagosome generation and maturation (8). Lipids underlie the formation of metastable, nanometer-sized microdomains within the plasma membrane (9), where signaling platforms presumably assemble to initiate phagocytosis (10-12). In addition, lipid species are required both as substrates for and as activators of enzymes responsible for the generation of important second messengers (8). Finally, specific lipid headgroups recruit proteins possessing lipid-binding domains and/or confer curvature and charge to the membrane surface, promoting electrostatic attraction and retention of proteins. The objective of this review is to highlight the importance of lipids as primary directors of protein targeting and membrane trafficking, using phagosome formation and maturation as a paradigm. 


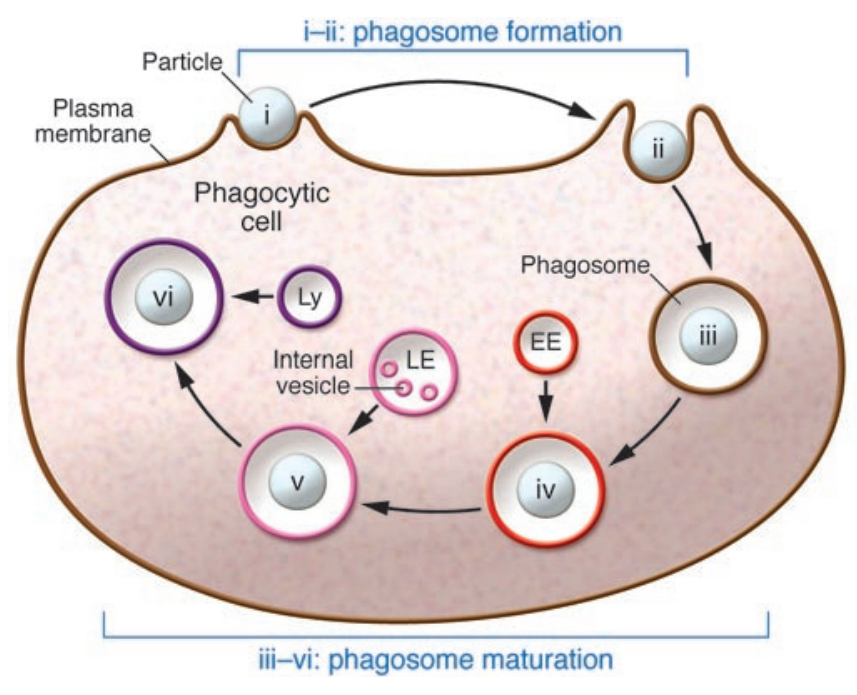

\section{Lipid metabolism during phagosome formation and maturation}

Lipids are key to normal phagocytosis. However, in several instances pathogenic microorganisms either co-opt or disrupt lipid metabolism to modulate phagosome maturation, and there are also cases in which defective phagosomal lipid metabolism can result in disease. To facilitate comprehension of the clinical abnormalities associated with phagosome formation and maturation, we begin with a brief description of lipid metabolism along the phagocytic process.

Phosphoinositide species. Phosphatidylinositol (PI) constitutes approximately $10 \%$ of the total lipid on the inner leaflet of the plasma membrane (8) and is thus a major component of the forming phagosome. The inositol ring of PI can be phosphorylated at any one of three positions (D-3, D-4, and D-5) to yield monophosphoinositides that can be further phosphorylated to bis- and trisphosphorylated species. Most, but not all, known phosphoinositide species have been identified on forming and/or maturing phagosomes (8) and are briefly discussed below.

$\mathrm{PI}-4,5$-bisphosphate $\left[\mathrm{PI}(4,5) \mathrm{P}_{2}\right]$ (Figure $2 \mathrm{~A}$ ) is constitutively present in the plasma membrane, accounting for approximately $2 \%$ of the inner leaflet (8). It undergoes rapid and transient accumulation above basal levels at the site of particle engagement and propagates with the pseudopods as they extend around the particle (Figure $2 \mathrm{~B})$. The transient accumulation of $\mathrm{PI}(4,5) \mathrm{P}_{2}$ is probably due to the action of type I PI-4-phosphate [PI(4)P] 5-kinase (PIP5KI) (13). This enzyme is constitutively associated with the plasma membrane and is therefore present at the base of the phagosome when the phagocytic target engages its receptors $(13,14)$. Although initially quiescent, PIP5KI is activated by Rho-family GTPases and/or phosphatidic acid (PA), which is generated locally at the time of phagocytosis (15-17), resulting in the observed $\mathrm{PI}(4,5) \mathrm{P}_{2}$ accumulation.

As the pseudopods advance, $\mathrm{PI}(4,5) \mathrm{P}_{2}$ disappears from the base of the forming phagosome (14), becoming undetectable in the sealed vacuole (Figure $2 \mathrm{~B}) . \mathrm{PI}(4,5) \mathrm{P}_{2}$ can be eliminated either by degradation or by phosphorylation to $\mathrm{PI}-3,4,5$-trisphosphate $\left[\mathrm{PI}(3,4,5) \mathrm{P}_{3}\right]$ (Figure 2A). The appearance of inositol-3,4,5-trisphosphate $\left(\mathrm{IP}_{3}\right)$ and diacylglycerol (DAG) at sites of phagocytosis implicates PLC, particularly the $\gamma$ isoform (PLC $\gamma$ ), but phosphatases could also contribute to $\mathrm{PI}(4,5) \mathrm{P}_{2}$ hydrolysis. Degradation of $\mathrm{PI}(4,5) \mathrm{P}_{2}$ by phosphoinositide 4- and/or 5-phosphatases has been reported during endocytosis

\section{Figure 1}

Stages of phagosome formation and maturation. Six stages of phagocytosis are shown: i, particle engagement; i, phagocytic cup formation; iii, nascent phagosome (1-2 min after sealing); iv, early phagosome (2-10 min after sealing); $v$, late phagosome (10-30 min after sealing); vi, phagolysosome (>30 min after sealing). As the phagosome matures, it undergoes multiple sequential interactions with early endosomes (EE), late endosomes (LE), and lysosomes (Ly).

(18), but has not yet been documented in phagocytosis. Of note, the 5-phosphatase synaptojanin 2 associates with Rac1 (19) and might contribute to $\mathrm{PI}(4,5) \mathrm{P}_{2}$ removal during phagosome closure.

Significantly, some of the $\mathrm{PI}(4,5) \mathrm{P}_{2}$ escapes degradation and is converted to $\mathrm{PI}(3,4,5) \mathrm{P}_{3}$ by class I $\mathrm{PI} 3 \mathrm{~K}$. $\mathrm{PI}(3,4,5) \mathrm{P}_{3}$ is readily detectable at the phagocytic cup shortly after particle engagement and remains present in the phagosomal membrane for approximately $1 \mathrm{~min}$ after sealing (Figure 2B) (20). Two molecules can terminate the accumulation of $\mathrm{PI}(3,4,5) \mathrm{P}_{3}$ : $\mathrm{SH} 2$ domain-containing inositol 5-phosphatase (SHIP; refs. 21-23), which is recruited to the phagocytic cup, and phosphatase and tensin homolog (PTEN), a 3'-phosphatase. The latter does not accumulate at sites of phagocytosis, which suggests that this enzyme has a more global effect (24).

PI-3-phosphate [PI(3)P] (Figure 2A) is normally found on early endosomes. It is first detectable on the phagosome within 1-2 min of sealing and persists for approximately $10 \mathrm{~min}$ (Figure 2B) (20). Phagosomal PI(3)P is generated largely by phosphorylation of PI by the class III PI3K, hVps34 (25). Accordingly, injection of inhibitory antibodies specific for Vps34 into phagocytic cells precludes PI(3)P accumulation on phagosomes (20). The mechanism whereby $\mathrm{PI}(3) \mathrm{P}$ is removed from the maturing phagosome remains unclear. It might simply revert to PI through the action of 3 -phosphatases of the myotubularin family. Alternatively, PI(3)P might be further phosphorylated to PI 3,5-bisphosphate $\left[\mathrm{PI}(3,5) \mathrm{P}_{2}\right]$ (Figure 2A) by FYVE finger-containing phosphoinositide kinase (PIKfyve), which is itself recruited to sites of PI(3)P enrichment by its FYVE domain (Figure 2B) $(26,27)$.

Phosphatidylserine. Phosphatidylserine (PS) (Figure 2A) is enriched in the plasma membrane, specifically the inner leaflet, where it constitutes at least $15 \%$ of the lipid (28). In stark contrast, little PS is detectable in the outer leaflet of healthy, quiescent cells (28). This asymmetric distribution is lost during apoptosis, and appearance of PS on the outer surface serves to identify cells destined for phagocytosis and degradation (29). However, in addition to the transmembrane scrambling seen in the target apoptotic cell, externalization of PS has also been suggested to occur in the membrane of the phagocytic cell (30). The ATP-binding cassette transporter 1 (ABC1) is thought to mediate externalization of PS, and this event might be an essential requirement for some forms of phagocytosis $(30,31)$.

At present, little is known about PS distribution, metabolism, and function during the course of phagosome maturation. Gross biochemical studies suggest that its levels remain relatively unchanged between early and late phagosomes, at approximately $10 \%$ of the total phospholipid content (32), but the transmembrane disposition of PS is not known. Potential roles of PS in phagosome maturation are further discussed below with respect to surface charge.

PA. PA (Figure 2A) accounts for 1\%-2\% of cellular lipid (28) and is now appreciated as an important second messenger involved in cell survival and proliferation, vesicular traffic, and cytoskeletal rearrangement (33). In mammalian cells, PA can be generated by either phospholipase D-mediated (PLD-mediated) hydrolysis of 
A

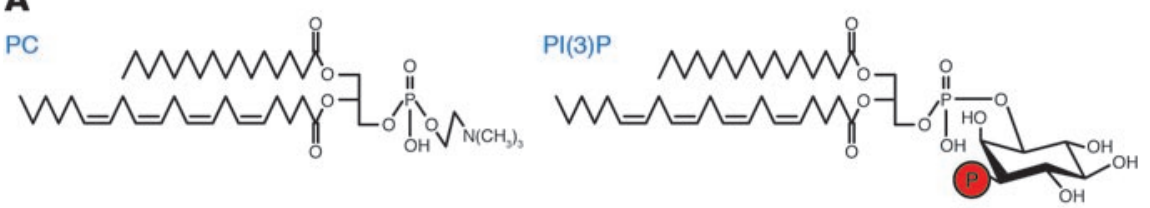

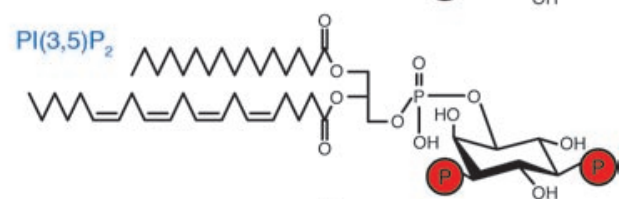

MS
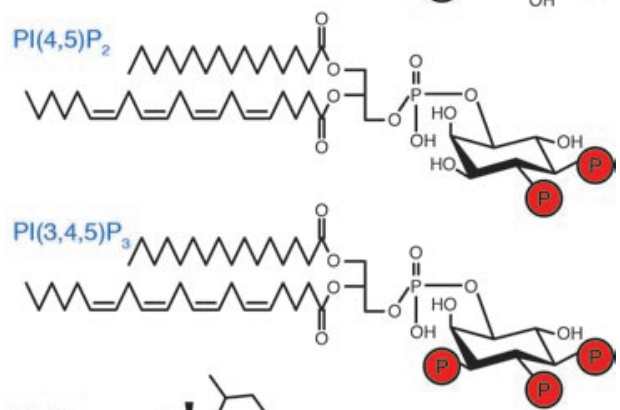

\section{Figure 2}

Lipids dictate domain-specific targeting of proteins during phagocytosis. (A) Structures of the principal phospholipids within the plasma and phagosomal membranes. The phospholipids have a glycerol backbone to which fatty acyl residues are attached at the sn- 1 and sn-2 positions. For simplicity, in all cases the common pairing of stearoyl and arachidonyl fatty acids are depicted in the sn-1 and $s n-2$ positions, respectively. The headgroups that define the lipid species attach to the glycerol backbone at the sn-3 hydroxyl group. The inositol ring of the phosphoinositides can be phosphorylated at any one of three positions (D-3, D-4, and D-5) to yield the various mono-, bis-, and tris-phosphorylated species. DAG and cholesterol (Chol) are also illustrated. PE, phosphatidylethanolamine. (B) The stages of phagocytosis from Figure 1 are shown, with the presence of specific lipids illustrated by the respective colors. Representative proteins attaching to specific lipids are shown, matched by color. Colored segments at stages with multiple lipids do not reflect subdomains or the relative abundance of the different species. Myo10, myosin X. Btk, Bruton agaggaglobulinemia tyrosine kinase.

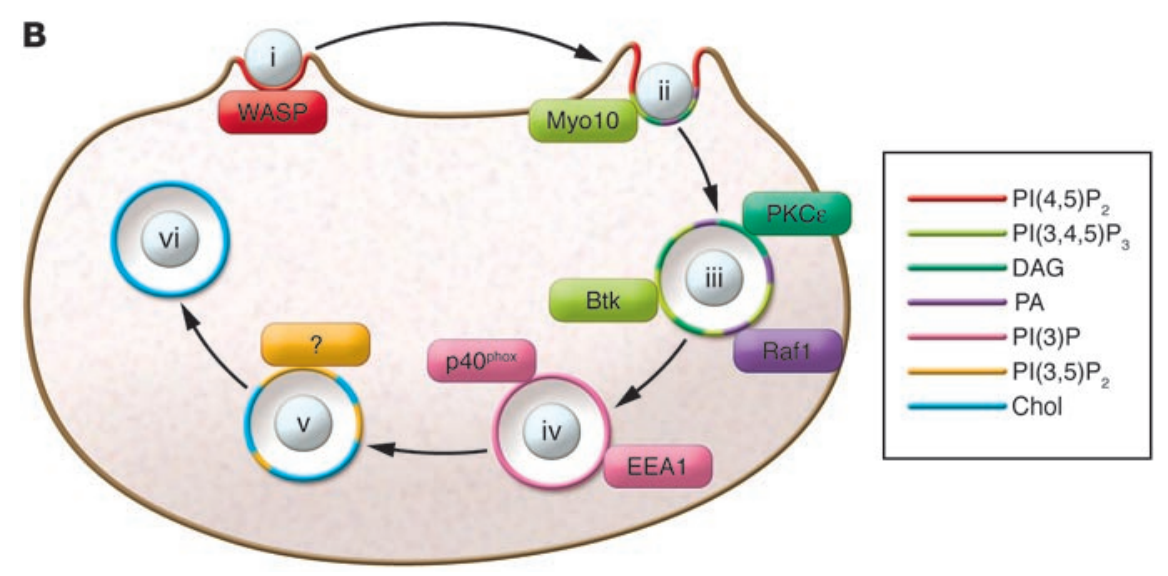

phosphatidylcholine (PC) or phosphorylation of DAG by DAGkinase (33). The former pathway might be an important component of a phagosomal lipid signaling loop in which $\mathrm{PI}(4,5) \mathrm{P}_{2}$ activates PLD to produce PA, while PA stimulates type I PIP5KIs, yielding more $\mathrm{PI}(4,5) \mathrm{P}_{2}(34)$. Aspects of the $\mathrm{PLD}$ pathway have been studied in phagocytes $(35,36)$, but to date there are no definitive measurements of the PA content of phagosomes and no quantitative attribution of its source.

Cholesterol. The planar and rigid nature of cholesterol (Figure 2A) allows it to preferentially associate with sphingolipids in membrane microdomains. These plasma membrane "rafts" have been implicated in a multitude of cellular processes such as signal transduction and membrane trafficking (reviewed in ref. 9), including membrane delivery to the phagocytic cup (37). Less appreciated is the differential distribution of cholesterol among different endocytic compartments. For example, lysosomes have comparatively little cholesterol, whereas late endosomes are cho- lesterol rich. Most of the cholesterol in late endosomes is found in the internal vesicles that have earned late endosomes the alternative designation multivesicular bodies (MVBs) (38). Moreover, various microdomains on late endosomes, on both the limiting and the intraluminal vesicle membranes, have been recently described (39). They differ in their composition and physical properties, which might have an impact on protein and lipid sorting. It is interesting to consider whether a similarly rich network of microdomains is present on phagosomes and whether cholesterol influences phagosome motility and the partition of Rab proteins, as described for endosomes (40). In this regard, maturing phagosomes have been found to gradually accumulate cholesterol (Figure 2B), which segregates in microdomains enriched with flotillin-1, heterotrimeric $\mathrm{G}$ proteins, and subunits of the vacuolar-type ATPase (V-ATPase), the proton pump responsible for phagosomal acidification $(4,32$, $41,42)$. These crude observations raise the tantalizing possibility that signaling and ion transport platforms exist in phagosomes. 
Table 1

Lipids and the protein domains to which they bind

\begin{tabular}{|c|c|c|c|}
\hline Species & $\begin{array}{l}\text { Protein-binding } \\
\text { domain }\end{array}$ & $\begin{array}{l}\text { Representative } \\
\text { protein }\end{array}$ & Reference \\
\hline $\mathrm{PI}(3) \mathrm{P}$ & $\begin{array}{l}\text { PX } \\
\text { FYVE }\end{array}$ & $\begin{array}{l}\text { p40phox } \\
\text { EEA1 }\end{array}$ & $\begin{array}{c}102 \\
52\end{array}$ \\
\hline $\mathrm{PI}(3,4) \mathrm{P}_{2}$ & $\begin{array}{l}\mathrm{PH} \\
\mathrm{PX}\end{array}$ & $\begin{array}{l}\text { TAPP1 } \\
\text { p47phox }\end{array}$ & $\begin{array}{l}115 \\
102\end{array}$ \\
\hline $\mathrm{PI}(3,5) \mathrm{P}_{2}$ & - & Atg18 & 116 \\
\hline $\mathrm{PI}(4,5) \mathrm{P}_{2}$ & $\begin{array}{c}\text { PH } \\
\text { FERM } \\
\text { ANTH } \\
\text { ENTH } \\
\text { Tubby } \\
\text { AP2- } \alpha \\
\text { Polycationic motif }\end{array}$ & $\begin{array}{l}\text { PLD2 } \\
\text { Ezrin } \\
\text { AP180 } \\
\text { Epsin } \\
\text { Tubby } \\
\text { AP2- } \alpha \\
\text { WASP }\end{array}$ & $\begin{array}{c}117 \\
118 \\
119 \\
120 \\
121 \\
122 \\
47\end{array}$ \\
\hline $\mathrm{PI}(3,4,5) \mathrm{P}_{3}$ & $\mathrm{PH}$ & Btk, myosin X & 65,123 \\
\hline DAG & $\mathrm{C} 1$ & PKC $\varepsilon$ & 67 \\
\hline PS & $\begin{array}{c}\mathrm{C2}^{\mathrm{A}} \\
\text { F5F8 type } \mathrm{C} \text { or } \\
\text { discoidin-type } \mathrm{C2}\end{array}$ & $\begin{array}{c}\text { PKC } \\
\text { Lactadherin, } \\
\text { Factor VIII }\end{array}$ & $\begin{array}{c}124 \\
91\end{array}$ \\
\hline PA & - & Raf1 & 79 \\
\hline \multirow[t]{3}{*}{$\begin{array}{l}\text { Negative } \\
\text { surface }\end{array}$} & $\begin{array}{l}\text { Polycationic motif + } \\
\text { hydrophobic residues }\end{array}$ & RGK GTPases & 89 \\
\hline & $\begin{array}{l}\text { Polycationic motif + } \\
\text { myristoylation }\end{array}$ & MARCKS & 90 \\
\hline & $\begin{array}{l}\text { Polycationic motif + } \\
\text { prenylation }\end{array}$ & K-Ras4B & 89 \\
\hline
\end{tabular}

ANTH, AP180 N-terminal homology; AP180, assembly protein 180; AP2- $\alpha$, adaptor related protein complex $2, \alpha 1$ subunit; Atg18, autophagy-related protein 18; Btk, Bruton agammaglobulinemia tyrosine kinase; ENTH, epsin N-terminal homology; FERM, 4.1-ezrin-radixin-moesin; PLD2, phospholipase D2; RGK, Rem1, Rem2, Rad, Gem, and Kir; TAPP1, tandem PH domain-containing protein 1. ${ }^{A}$ Conventional $\mathrm{C} 2$ domains are not PS-specific, but recognize anionic lipids in general.

\section{Protein recruitment to phagosomal lipids mediated by lipid-binding modules}

The lipids described above play multiple roles as determinants of phagosomal formation and fate. Lipids serve these functions in part by influencing membrane curvature and by contributing predominantly to the surface charge of the bilayer. However, the best studied and probably most important function of the lipids is coordination of the recruitment and retention of key phagocytic proteins. This is accomplished mainly by the selective interaction between specialized protein modules and their target lipids.

Structural and kinetic considerations. Lipid-binding modules represent a class of protein domains or motifs that reversibly bind the headgroups of specific lipids (Table 1). In combination with spatially and temporally restricted lipid metabolism, as described above for phagocytosis, such modules target proteins to discrete membrane surfaces and enable a coordinated signaling response. Structural details pertaining to lipid-binding domains have been recently reviewed $(43,44)$ and are not further discussed here.

A nimble signaling molecule must associate quickly with its target to initiate a response and should dissociate equally swiftly to terminate it. To ensure proper specificity with rapid on/off kinetics, it is more effective to have multiple, comparatively low-affinity targeting determinants instead of a single, high-affinity one. The avidity of such an interaction is high only when multiple determinants are ligated concomitantly. In this context, lipid-binding domains often function in cooperation with other targeting domains as one part of a multicomponent detection system able to recognize coincident membrane-targeting motifs $(44,45)$. By continuously cycling between lipid-bound and unbound states, lipid-targeting domains can effectively sample the local lipid concentration (43) and respond promptly to changes in lipid metabolism. This might be particularly important in the case of the phosphoinositides, which are abundant on forming and/or maturing phagosomes and have high turnover rates (46).

How individual lipids contribute to protein targeting depends on their structure and relative abundance. These properties are best illustrated by the phosphoinositides and their respective binding domains. Because of the high abundance of $\mathrm{PI}(4,5) \mathrm{P}_{2}$, proteins that bind to it can have comparatively lower selectivity and affinity (47). In contrast, domains that target rare 3-phosphoinositides must do so with greater specificity and affinity. Pleckstrin homology $(\mathrm{PH})$ domains that bind $\mathrm{PI}(3,4,5) \mathrm{P}_{3}$ with high affinity deploy multiple basic residues to engage the three phosphate groups in a strong hydrogen bond network $(48,49)$. FYVE and Phox homology (PX) domains, which recognize the monophosphorylated PI(3)P, use different strategies. In these cases, increased affinity results from simultaneous electrostatic interaction with the 3-phosphate and penetration of the membrane by nonpolar residues $(50,51)$. In the case of some FYVE domain-containing proteins, dimerization increases binding avidity (52).

Despite its importance, no consensus PA-binding structure has emerged to date. The known proteins that bind PA all present basic amino acids at the lipid-interacting surface but have no definitive sequence or structural homology. The propensity for PA to form hydrogen bonds, along with its negative charge, have been proposed as primary factors for making PA a favored docking site for basic residues (53).

Lipid-binding modules in phagocytosis. Lipids play an essential role in phagocytosis: recruiting, retaining, and functionally regulating the activity of a myriad of proteins (8). $\mathrm{PI}(4,5) \mathrm{P}_{2}$ is key to cytoskeletal remodeling during pseudopod extension and particle engulfment, promoting de novo actin nucleation $(54,55)$, removing capping proteins from the barbed ends of actin filaments (56), activating filament-severing proteins like gelsolin (57), and promoting filament cross-linking (58). Many of the actin-regulatory proteins possess polycationic motifs $(59)$ that are attracted electrostatically to $\mathrm{PI}(4,5) \mathrm{P}_{2}$. Notably, in combination with GTP-bound Cdc42, $\mathrm{PI}(4,5) \mathrm{P}_{2}$ binding activates the Wiskott-Aldrich syndrome protein (WASP) to induce actin assembly. Mutations in the lipid-binding domain of WASP prevent plasma membrane localization and cytoskeletal rearrangement (60). In addition, $\mathrm{PI}(4,5) \mathrm{P}_{2}$ can be recognized stereospecifically by PH, 4.1-ezrin-radixin-moesin (FERM), AP180 N-terminal homology (ANTH), and epsin N-terminal homology (ENTH) domains (Table 1). Ezrin, a prototypical FERM domain-containing protein known to anchor actin to membranes, has been detected on phagosomes (61) and was implicated in modulating maturation (62). Identification of additional $\mathrm{PI}(4,5) \mathrm{P}_{2}$ ligands at sites of phagocytosis is pending.

$\mathrm{PI}(4,5) \mathrm{P}_{2}$ is promptly removed from nascent phagosomes, which coincides with actin disassembly. In its wake, $\mathrm{PI}(3,4,5) \mathrm{P}_{3}$ accumulates and serves as a binding target for the $\mathrm{PH}$ domains of adaptor proteins such as growth factor receptor-bound protein 2-associated binder protein 1 (GAB1) and GAB2, which are crucial for the assembly of the signaling platform generated by phagocytic receptors (63). Although 

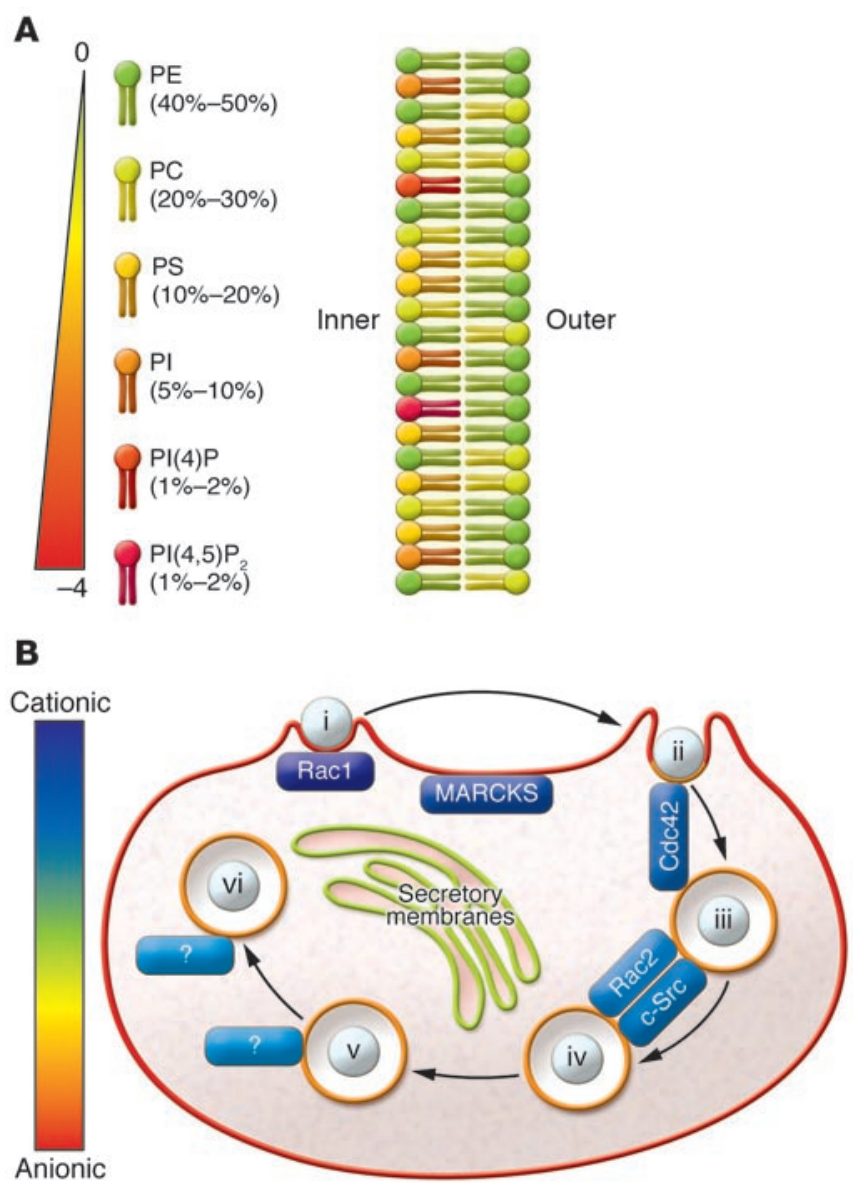

its accumulation is short-lived, $\mathrm{PI}(3,4,5) \mathrm{P}_{3}$ serves as an important targeting signal. It helps recruit WASP family verprolin-homologous protein (WAVE; ref. 64) and myosin X (65) to forming phagosomes, contributing to the assembly of the cytoskeletal machinery that drives pseudopod extension and sealing (Figure 2B).

$\mathrm{PI}(3,4,5) \mathrm{P}_{3}$ also promotes recruitment to the phagocytic cup of $\mathrm{PLC} \gamma$ via its $\mathrm{PH}$ domain (66). PLC $\gamma$ stimulates further $\mathrm{PI}(4,5) \mathrm{P}_{2}$ hydrolysis while simultaneously generating DAG. Confined to the membrane of the forming phagosome (Figure 2), DAG serves as a docking site for proteins possessing $\mathrm{C} 1$ domains, such as PKD, RasGRP, DAG kinases, and, more notably, the classical and novel PKC isoforms $(67,68)$, which can contribute to phagosome formation and maturation and/or the inflammatory response (Figure $2 \mathrm{~B}$ ).

Phosphoinositides are also instrumental in the deployment of the phagosomal antimicrobial armamentarium. The NADPH oxidase complex responsible for superoxide generation assembles at the membrane in a manner dependent on the PX domain of its $\mathrm{p} 47$ phox subunit (69), which is soluble prior to the onset of phagocytosis. The PX domain of $\mathrm{p} 47$ phox has preferential affinity for $\mathrm{PI}(3,4) \mathrm{P}_{2}(43)$.

$\mathrm{PI}(3) \mathrm{P}$, which appears shortly after the phagosome seals, serves two primary functions in the course of maturation. The first involves association with various effectors that recognize its headgroup and are recruited to phagosomes to coordinate fusion events with late endosomes (1). EEA1 accumulates on early phagosomes in part by binding to PI(3)P through its FYVE domain (Figure 2B), and it is thought to both bridge and support the fusion of Rab5and Rab4-bearing membranes (25). Hepatocyte growth factor-reg-

\section{Figure 3}

Contribution of phospholipid species to membrane composition and charge. (A) Schematic representation of the lipid composition of the plasma membrane. The color of the headgroup not only identifies the different species, but is indicative of its charge. The relative mole ratio of the lipids is shown in parentheses. (B) Anionic lipids dictate electrostatic targeting of proteins during phagocytosis. The stages of phagocytosis from Figure 1 are shown, with the relative charge of membranes or ligand proteins illustrated by color. Note that the plasmalemma is most negative, and secretory membranes are least negative. The phagosome membrane has an intermediate negativity, and polycationic proteins are shown in varying shades according to their charges.

ulated tyrosine kinase substrate (Hrs) is similarly anchored to early phagosomal PI(3)P through a FYVE domain (70). It mobilizes the multimeric endosomal sorting-complex required for transport (ESCRT), which propels inward membrane budding during MVB formation (71). Although the multivesicular nature of the phagosome is not well established, there is evidence of intraphagosomal vesicles (72). Hrs has been directly implicated in phagosome maturation: its depletion leads to a decrease in LBPA and abrogates the luminal acidification seen in fully mature phagosomes (70).

$\mathrm{PI}(3) \mathrm{P}$ also helps activate NADPH oxidase $(73,74)$. Oxidant generation by NADPH oxidase in phagosomes requires the $\mathrm{p} 40$ subunit ( $\left.\mathrm{p} 40^{\mathrm{phox}}\right)$, which is recruited to the phagosomal membrane via its PI(3)P-binding PX domain (Figure 2B) $(73,74)$. Rac initiates and maintains the assembly of the active oxidase complex at the plasma membrane, whereas other factors seem to be necessary for oxidase function in the phagosome, ostensibly because Rac detaches from the membrane of the phagosome after sealing (75). p40 ${ }^{\text {phox }}$ might substitute for Rac in maintaining the NADPH oxidase active in the early phagosomes.

Because there are no known selective, high-affinity $\mathrm{PI}(3,5) \mathrm{P}_{2}$ binding domains, it has not yet been possible to visualize this lipid over the course of phagosome maturation. For this reason, the existence of $\mathrm{PI}(3,5) \mathrm{P}_{2}$ on phagosomes, let alone its function, remains speculative. Nevertheless, some indirect data provide hints of its probable localization and function. The yeast homolog of PIKfyve, Fab1p, has been shown to be a regulator of vacuolar sorting (76, 77). Moreover, work in mammalian cells has implicated $\mathrm{PI}(3,5) \mathrm{P}_{2}$ in the maintenance of endomembrane integrity, morphology, and progression $(26,78)$. By extension, PIKfyve and its product $\mathrm{PI}(3,5) \mathrm{P}_{2}$ are expected to contribute to phagosome maturation. A recently characterized PIKfyve inhibitor should facilitate evaluation of the function of the enzyme and its lipid product in phagocytosis (78).

In addition to the phosphoinositides and their degradation products, other lipids also feature prominently in protein recruitment and activation on the maturing phagosome. PA is important in this context because it contributes to the assembly and activation of NADPH oxidase by interacting directly with p47phox and is a potent activator of a number of protein and lipid kinases, including Fgr, the type I PIP5KI, and sphingosine 1-phosphate kinase (79).

\section{Curvature as a determinant of protein recruitment to the phagosomal membrane}

Membrane trafficking and remodeling often require the lipid surface to undergo deformations. The resulting changes in curvature are now understood to contribute to membrane dynamics by modulating the local lipid composition, altering the exposure of hydrophobic moieties, and serving as a ligand for curvature sensors (44). 


\section{Table 2}

Intracellular pathogens and their effectors that modulate phagosomal lipid metabolism

\begin{tabular}{|c|c|c|c|}
\hline Pathogen & Effector & Effect & Ref \\
\hline Salmonella enterica & SigD & $\begin{array}{l}\text { Phosphoinositide phosphatase that acts on } \mathrm{PI}(4,5) \mathrm{P}_{2} \text { and } \mathrm{PI}(3,4,5) \mathrm{P}_{3} \text { to trigger } \\
\text { invasion into the host cell, activate host cell survival pathways, and contribute to the } \\
\text { formation of a replicative vacuole }\end{array}$ & 95,96 \\
\hline Shigella flexneri & $\operatorname{lpg} \mathrm{D}$ & $\begin{array}{l}\text { Phosphoinositide phosphatase that converts } \mathrm{PI}(4,5) \mathrm{P}_{2} \text { to } \mathrm{PIP} \text {, thereby triggering } \\
\text { invasion and activating host cell survival pathways }\end{array}$ & 95 \\
\hline Legionella pneumophila & SidC and SidA & $\begin{array}{l}\text { Proposed to bind } \mathrm{PI}(4) \mathrm{P} \text { and aid in the formation of the replicative vacuole } \\
\text { within the host cell }\end{array}$ & 95,98 \\
\hline \multirow[t]{2}{*}{ Mycobacterium tuberculosis } & LAM & $\begin{array}{l}\text { Glycosylated PI analog that inhibits the activation of Vps34 to } \\
\text { limit PI(3)P production on the intracellular vacuole }\end{array}$ & 100 \\
\hline & SapM & Phosphatase that converts $\mathrm{PI}(3) \mathrm{P}$ to $\mathrm{PI}$, contributing to phagosomal arrest & 101 \\
\hline
\end{tabular}

LAM, lipoarabinomannan.

PA exemplifies the role of curvature in modulating membrane dynamics and protein recruitment. PA holds the distinction of being the only anionic cone-shaped lipid (80), and in the presence of divalent cations, it segregates into PA-rich domains (81). This combination of negative curvature (bending the bilayer around the lipid headgroup) and phase separation properties promotes membrane fission in model systems $(82,83)$ and might drive similar processes in phagocytosis. Moreover, the negative curvature induced in areas of PA aggregation increases the exposure of alkyl chains to the surrounding environment. Because interaction with the aqueous medium is thermodynamically unfavorable, alkyl chain exposure promotes hydrophobic interactions between PA and proteins. Not surprisingly, many PA-binding domains contain hydrophobic residues. Of note, PA promotes the docking of trafficking-related proteins, such as ADP-ribosylation factor (ARF), kinesin, and N-ethylmaleimide-sensitive factor (NSF) (79).

LBPA is an example of an inverted cone-shaped, fusogenic lipid whose capacity to induce positive membrane curvature (bending the membrane away from the lipid headgroups) can modulate membrane dynamics and function (84). In particular, this lipid has the intrinsic ability to drive membrane deformation and invagination in the presence of a $\mathrm{pH}$ gradient similar to that generated by the V-ATPase between the cytosol and the lumen of late endosomes (84). In fact, the tendency of LBPA to segregate and induce invagination is thought to underlie the formation of internal vesicles within late endosomes.

More generally, membrane curvature is itself a determinant of membrane binding for some proteins with a unique banana-like shape. For example, BAR (Bin, amphiphysin, and Rvs) domains dimerize and assume a curved coiled-coil structure that abuts the lipid bilayer. These domains are thought to either sense or stabilize a curved membrane surface (44). Interestingly, BAR domains are often found in close proximity to other lipid-binding domains, such as $\mathrm{PH}$ and PX domains. Together, these lipid sensors might function as a coincidence detection unit. For example, sorting nexin-1 (SNX1) is targeted to the highly curved endosomal surface through the joint activities of its PI(3)P-binding PX and curvature-sensing BAR domains (45). Whether sorting nexins or similar coincidence detection units operate in phagosomes remains to be demonstrated.

\section{Charge as a determinant of protein recruitment to the phagosomal membrane}

Approximately one-fifth of the plasma membrane consists of anionic phospholipids, with most found at the inner leaflet (Fig- ure $3 \mathrm{~A})$. The anionic character of the lipids confers to the inner surface an electrostatic potential. The biophysical implications of a negative membrane surface are multiple and complex (see ref. 85 for theoretical details). Briefly, they produce an electric field that attracts the cationic molecules, such as inorganic ions and cationic peptides, within approximately $1 \mathrm{~nm}$ of the membrane (a distance termed the Debye length). The electrostatic potential associated with the electric field is termed the surface potential and is distinct from the more familiar transmembrane electrical potential difference. The latter is an electrodiffusional voltage attributable to differences in membrane permeability to various inorganic ions. An integral membrane protein can sense the sum of the transmembrane potential and the difference in intra- and extracompartmental surface potentials. In contrast, peripheral proteins experience only the electrostatic forces of the surface potential.

Lipids and proteins affect each other reciprocally within the Debye length. Cationic peptides that interface with the membrane, such as the cationic domain of the myristoylated alanine-rich C-kinase substrate (MARCKS) protein, can attract and sequester anionic phospholipids into functional pools; removal of the peptide from the membrane releases the lipids to act on downstream effectors, such as other lipid-binding domains (86). Because of their greater responsiveness to electrostatic attraction, the polyvalent phospholipids [such as $\mathrm{PI}(4,5) \mathrm{P}_{2}$ ], and not monovalent lipids, are the primary targets of sequestration by membraneadsorbed polybasic peptides $(87,88)$.

On the other hand, the negative surface manifestly serves as a targeting motif for various signaling proteins. A polybasic domain alone, however, is insufficient to localize most proteins to the membrane. Accordingly, the polybasic domain often works in conjunction with a second membrane-targeting motif such as myristoyl or prenyl moieties or the side-chains of hydrophobic amino acids (89). The electrostatic interaction with the surface charge provides cells with a binary electrostatic switch to target cationic proteins to the membrane in a regulated fashion (90). If the charge of the protein is altered, its affinity for the negative surface diminishes, potentially causing it to dissociate from the membrane. A reduction in the net charge of a protein can be brought about by phosphorylation or by its association with an anionic protein such as calmodulin.

A less appreciated way to toggle the electrostatic switch is to alter the surface charge through changes in lipid metabolism, such as those experienced by the membrane during phagocytosis. To better understand how lipid metabolism affects surface charge, our lab- 


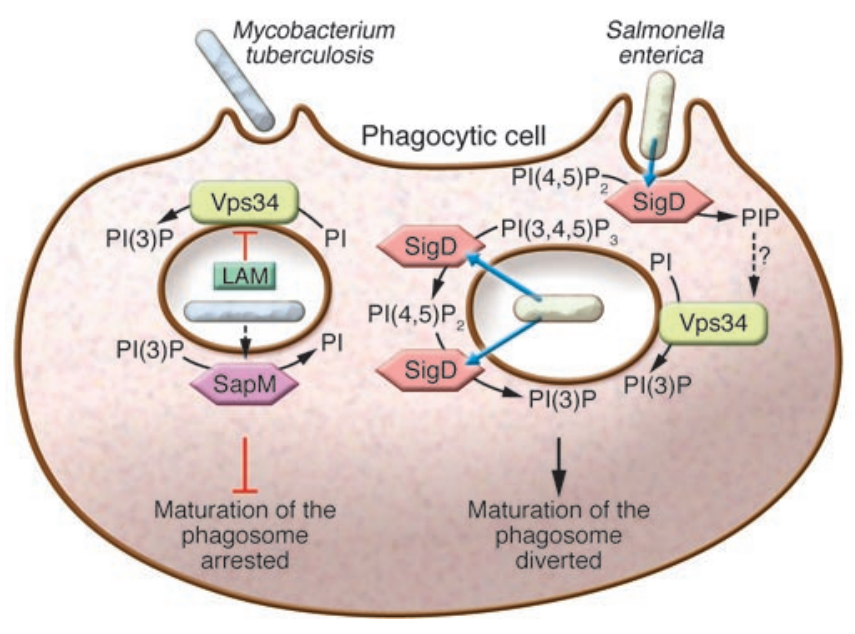

oratory developed genetically encoded biosensors to quantify the surface charge on the inner leaflet during phagocytosis in live cells (75). In resting cells, the most cationic sensors exclusively target the cytosolic leaflet of the plasma membrane, highlighting its anionic nature. Strikingly, the surface charge of the invaginating phagosomal membrane was found to drop precipitously, whereas the unengaged areas of the plasma membrane remained unaltered (Figure $3 \mathrm{~B})$. The alteration in charge was associated with, and is probably attributable to, the drop in $\mathrm{PI}(4,5) \mathrm{P}_{2}$ levels described above (75).

Several questions follow from this initial observation. What is the fate of the phagosomal surface charge along the maturation pathway, and which lipids contribute to the evolution of charge of the phagosome? Are the polyvalent phosphoinositides the primary determinants of surface charge, as in the case of phagosome formation, or are monovalent species (such as PS) responsible? The cytosolic leaflet of the endocytic pathway was found to be negatively charged, although less so than the plasma membrane (91). Interestingly, this negativity was conferred to the phagosomes largely by PS and not by phosphoinositides (91). That moderately cationic proteins, such as c-Src, Rac2, and Cdc42, localized to membranes rich in PS suggests that the accumulation of the anionic phospholipid plays a direct role in protein targeting (Figure 3B) (91).

Other lipids must surely contribute to the adjustment of phagosomal surface charge, although confirmation awaits the development of suitable probes. The generation of the anionic PA through the hydrolysis of the uncharged and highly abundant PC is expected to increase the negative charge density, as would rare inositide species like $\mathrm{PI}(3) \mathrm{P}$ and $\mathrm{PI}(3,5) \mathrm{P}_{2}$. At the late phagosomal stage, LBPA would add its negative charges to the phagosomal surface, although its presence on the cytosolic leaflet has not been verified directly.

The study of surface electrostatics in regulating phagocytosis is still in its infancy, yet several examples of surface charge modulation affecting phagocytosis have already been documented. Detachment of membrane-associated MARCKS during phagosome formation (Figure 3B) has been demonstrated (92), although its functional significance remains unclear (93). Potentially more relevant are the effects of surface potential on small GTPases, such as Rac1, that bear polycationic motifs in their hypervariable region (Figure 3B). Activation of such GTPases by nucleotide exchange factors requires prior dissociation from GDP dissociation inhibitor (GDI). We have suggested that the surface charge of the plasma membrane functions as the elusive GDI-dissociating factor (GDF), preferentially

\section{Figure 4}

Intracellular bacteria co-opt or disrupt phagosomal lipid metabolism as a survival strategy. M. tuberculosis secretes the glycosylated PI analog lipoarabinomannan (LAM) to inhibit the production of $\mathrm{PI}(3) \mathrm{P}$ by Vps34 in addition to secreting the phosphatase SapM, which dephosphorylates $\mathrm{PI}(3) \mathrm{P}$. Together, these effectors decrease vacuolar $\mathrm{PI}(3) \mathrm{P}$ to arrest phagosome maturation and produce a favorable intracellular niche for M. tuberculosis survival. S. enterica injects the effector SigD into the cell. This phosphatase depletes $\mathrm{PI}(4,5) \mathrm{P}_{2}$ from the plasma membrane, leading to bacterial invasion into the host cell. Once inside, SigD has been suggested to dephosphorylate $\mathrm{PI}(3,4,5) \mathrm{P}_{3}$ to produce $\mathrm{PI}(3) \mathrm{P}$. Alternatively, SigD products might modulate Vps34 in order to increase vacuolar $\mathrm{PI}(3) \mathrm{P}$. These effects help the bacterium divert the maturation of the invasion vacuole away from the conventional antimicrobial trajectory of phagosomes.

trapping the small fraction of spontaneously dissociating Rac1GDP at the plasma membrane, in the immediate vicinity of the $\mathrm{GEF}(\mathrm{s})$ that are activated by phagocytic receptors (8). Conversely, active Rac1 is expected to dissociate from the plasmalemma when the surface charge drops upon $\mathrm{PI}(4,5) \mathrm{P}_{2}$ hydrolysis, and this has been verified experimentally (75). Of note, constitutively active mutants of Rac1 are also lost from sealing phagosomes with identical kinetics, implying that dissociation is not caused by GTP hydrolysis and therefore cannot be attributed to termination of exchange factor activity or to activation of GTPases (75). These early data point to surface charge as an important determinant of protein targeting and dissociation along the course of phagocytosis.

\section{Clinical examples of defective phagosomal lipid metabolism and its subversion by pathogens}

Bacterial interference with phagosomal lipid metabolism as a survival strategy. Because lipids are key contributors to phagosome generation and microbicidal function, it is not surprising that many pathogens have evolved ways of either co-opting or obstructing phagosomal lipid metabolism as a survival strategy (Table 2). A prototypical example is Salmonella enterica, which injects into the host cells a phosphoinositide phosphatase, SigD (also known as SopB). This potent enzyme rapidly degrades $\mathrm{PI}(4,5) \mathrm{P}_{2}$ on the host cell membrane to PI phosphate (PIP), thereby subverting cytoskeletal dynamics to facilitate bacterial entry and diverting maturation of the invasion vacuole to a nonlytic compartment. Although accumulated at the outer tips of the invasion ruffles, $\mathrm{PI}(4,5) \mathrm{P}_{2}$ is depleted from the base of the ruffles (94). Depletion of the inositide coincides with, and is thought to contribute to, the dissociation of actin from the ruffle base, where the bacteria enter the cell. Actin disassembly is required for closure of the invasion vacuole and for its progression to become a bacterial survival and replication niche. The disappearance of $\mathrm{PI}(4,5) \mathrm{P}_{2}$ and/or the appearance of the products generated by SigD, most likely PI5-phosphate [PI(5)P], also play a key role in directing the traffic of membranes that culminates in the formation of the spacious replicative vacuole, where bacteria are sheltered from host bactericidal factors (95). SigD has also been proposed to produce PI(3)P through dephosphorylation of $\mathrm{PI}(3,4,5) \mathrm{P}_{3}$ (Figure 4) (96), thereby influencing not only vacuole formation but also its maturation.

In a similar fashion, the causative agent of Legionnaire disease, Legionella pneumophila, avoids the degradative phagosomal pathway after entry into macrophages, diverting the invasion vacuole away from lysosomes. The Legionella-containing vacuole (LCV) fuses instead with the benign secretory pathway. As in the case of S. enterica, phosphoinositides are central to the process whereby L. pneumophila 
reroutes intracellular traffic (95). PI3K has been implicated in LCV trafficking as well as in intravacuolar bacterial replication (97). More directly, the L. pneumophila effector protein SidC directly binds to PI(4)P (98), which accumulates on the LCV. By anchoring to the LCV via $\mathrm{PI}(4) \mathrm{P}$, this effector, along with its paralog SidA, is thought to link with host cell proteins to commandeer vesicle trafficking (95).

Yet another example of phosphoinositide involvement in the pathogenesis of infectious disease is provided by Mycobacterium tuberculosis. M. tuberculosis is unable to invade cells actively, but is internalized by macrophages into what is initially a conventional phagosome. Shortly after ingestion, the bacteria deploy a number of weapons that enable them to arrest the maturation process at an early stage, precluding progression to lytic phagolysosomes (99). The bacteria generate a favorable intracellular niche, in part by modulating the acquisition of PI(3)P by the vacuole (95). To limit the production of this inositide, the bacteria secrete the glycosylated PI analog lipoarabinomannan, which inhibits the activation of $\mathrm{Vps} 34$ (100). In concert, the bacteria secrete the acid phosphatase SapM, which dephosphorylates PI(3)P (101). The combined actions of these two effectors lower the vacuolar content of $\mathrm{PI}(3) \mathrm{P}$ and, in a manner that remains poorly understood, contribute to the arrest of phagosomal maturation at an early stage and favor intracellular survival of M. tuberculosis (Figure 4). These are but a few of the strategies used by bacteria to survive intracellularly; additional means of targeting host cell inositides by other pathogens are likely to emerge with future studies.

Clinical paradigms of defective phagocytosis. Inborn errors in lipid metabolism and/or signal modulation during the phagocytic process are also encountered in the clinical setting. For example, mutations that affect the binding of $\mathrm{PI}(3,4) \mathrm{P}_{2}$ to the PX domain of $\mathrm{p} 47 \mathrm{phox}$ impede the generation of reactive oxygen species by NADPH oxidase and can result in chronic granulomatous disease (102), a disease associated with recurrent and life-threatening infections. Similarly, individuals with Wiskott-Aldrich syndrome are immunodeficient and prone to autoimmune disease. In these patients the inositide-regulated protein WASP is defective. Because WASP is a key mediator of phagosome formation (103), WiskottAldrich patients exhibit impaired engulfment of opsonized particles and compromised removal of apoptotic cells (reviewed in ref. 104). The link between defective clearance of apoptotic cells and autoimmune disease is further discussed below.

Hereditary lipid-storage disorders, such as Gaucher disease, can impair phagocytic and bactericidal competence $(105,106)$. Gaucher disease is an autosomal-recessive glycolipid storage disorder that results from insufficient activity of lysosomal $\beta$-glucocerebrosidase, the enzyme responsible for glucosylceramide hydrolysis. In the clinic, Gaucher disease presents as a multisystem and heterogeneous disorder, with hepatosplenomegaly, anemia, thrombocytopenia, and bone pains. Particularly germane to this discussion, patients with Gaucher disease have increased risk of chronic or fulminant infections (105). Impaired macrophage and monocyte function probably contributes to this increased susceptibility. The suppressed $\beta$-glucocerebrosidase activity leads to the accumulation of glucosylceramide and other lipids in lysosomes. The resulting lipid-laden macrophages, termed Gaucher cells, are characteristic of the condition. Monocytes and macrophages from patients with Gaucher disease exhibit decreased bacterial killing and superoxide generation compared with matched controls $(105,106)$. Remarkably, the capacity of Gaucher cells to generate reactive oxygen species was restored to control levels by enzyme replacement therapy
(105). Glucosylceramide has been implicated in regulating membrane transport (107), and secondary biochemical pathways modulating PC metabolism are known to be altered in macrophage models of Gaucher disease (108); however, the detailed mechanisms by which phagocyte function is impaired remain elusive.

The clearance of apoptotic cells by phagocytosis during tissue development, remodeling, and homeostasis has particular significance in the contexts of resolution of inflammation and of autoimmunity. Lipids are critically involved in these events. As described above, the asymmetric distribution of PS in the plasma membrane is lost during apoptosis, and the externalized phospholipid engages PS receptors on macrophages (109-111) to initiate cell clearance. The ingestion of apoptotic cells is both antiinflammatory and nonimmunogenic. In addition to protecting neighboring tissues from exposure to the inflammatory contents of dying cells, the uptake of apoptotic cells causes macrophages to secrete antiinflammatory cytokines, such as TGF- $\beta 1$ and IL- 10 , while suppressing the secretion of the proinflammatory mediators TNF- $\alpha$ and IL-8 (29), which are normally produced upon macrophage engagement with pathogens. When apoptotic cells are no longer efficiently cleared, secondary necrosis can ensue, leading to exposure to self antigens and breaks in self tolerance. For example, mice lacking the protein milk fat globule EGF factor 8 (MFGE8) protein, implicated in PS recognition, exhibit signs of autoimmunity attributable to defects in apoptotic cell clearance (29). In humans, apoptotic cells represent the driving force behind the autoimmune response seen in SLE (112). Macrophages from patients with SLE have a diminished capacity to internalize apoptotic cells (113), the extent of which correlates with disease progression (114). The case of SLE highlights the necessity to effectively clear apoptotic cells by phagocytosis to avoid adverse inflammatory and immunogenic responses.

\section{Concluding remarks}

Phagocytosis is an archetype of an intricate cellular process choreographed by lipid metabolism. By serving as ligands for lipidbinding domains and conferring curvature and negative charge to the membrane, lipids coordinate the spatial and temporal redistribution and the activation of multiple protein effectors. In this fashion, lipids play a pivotal role in the generation and transduction of signals, in remodeling the cytoskeleton, and in guiding the fusion and fission events that define phagosome maturation. Derangements in lipid metabolism can have dire consequences on phagocytosis, which can result in infectious, inflammatory, and autoimmune disorders.

\section{Acknowledgments}

We apologize to the many scientists whose work we could not cite due to space limitations. We thank Tony Yeung and Greg Fairn for useful discussion. Original work in the authors' laboratory is supported by grant 7075 of the Canadian Institutes of Health Research (CIHR), the Canadian Cystic Fibrosis Foundation (CCFF), and the Heart and Stroke Foundation of Ontario. B.E. Steinberg is the recipient of studentships from the McLaughlin Centre for Molecular Medicine and the CIHR. S. Grinstein is the current holder of the Pitblado Chair in Cell Biology.

Address correspondence to: Sergio Grinstein, Program in Cell Biology, Hospital for Sick Children, 555 University Avenue, Toronto, Ontario M5G 1X8, Canada. Phone: (416) 813-5727; Fax: (416) 8135028; E-mail: sga@sickkids.ca. 
1. Vieira, O.V., Botelho, R.J., and Grinstein, S. 2002. Phagosome maturation: aging gracefully. Biochem.J. 366:689-704.

2. Scott, C.C., Botelho, R.J., and Grinstein, S. 2003 Phagosome maturation: a few bugs in the system. J. Membr. Biol. 193:137-152.

3. Trombetta, E.S., and Mellman, I. 2005. Cell biology of antigen processing in vitro and in vivo. Annu Rev. Immunol. 23:975-1028.

4. Garin, J., et al. 2001. The phagosome proteome: insight into phagosome functions. J. Cell Biol. 152: $165-180$

5. Rogers, L.D., and Foster, L.J. 2007. The dynamic phagosomal proteome and the contribution of the endoplasmic reticulum. Proc. Natl. Acad. Sci. U. S. A. 104:18520-18525.

6. Stuart, L.M., et al. 2007. A systems biology analysis of the Drosophila phagosome. Nature. 445:95-101.

7. Halet, G. 2005. Imaging phosphoinositide dynamics using GFP-tagged protein domains. Biol. Cell. 97:501-518

8. Yeung, T., and Grinstein, S. 2007. Lipid signaling and the modulation of surface charge during phagocytosis. Immunol. Rev. 219:17-36.

9. Hanzal-Bayer, M.F., and Hancock, J.F. 2007. Lipid rafts and membrane traffic. FEBS Lett. 581:2098-2104.

10. Kwiatkowska, K., Frey, J., and Sobota, A. 2003. Phosphorylation of FcgammaRIIA is required for the receptor-induced actin rearrangement and capping: the role of membrane rafts. J. Cell Sci. 116:537-550.

11. Barnes, N.C., et al. 2006. Raft localisation of FcgammaRIIa and efficient signaling are dependent on palmitoylation of cysteine 208. Immunol. Lett. 104:118-123.

12. Garcia-Garcia, E., Brown, E.J., and Rosales, C. 2007. Transmembrane mutations to FcgammaRIIA alter its association with lipid rafts: implications for receptor signaling. J. Immunol. 178:3048-3058.

13. Coppolino, M.G., et al. 2002. Inhibition of phosphatidylinositol-4-phosphate 5-kinase Ialpha impairs localized actin remodeling and suppresses phagocytosis. J. Biol. Chem. 277:43849-43857.

14. Botelho, R.J., et al. 2000. Localized biphasic changes in phosphatidylinositol-4,5-bisphosphate at sites of phagocytosis. J. Cell Biol. 151:1353-1368.

15. Oude Weernink, P.A., Schmidt, M., and Jakobs, K.H 2004. Regulation and cellular roles of phosphoinositide 5-kinases. Eur. J. Pharmacol. 500:87-99.

16. Tolias, K.F., et al. 2000. Type Ialpha phosphatidylinositol-4-phosphate 5-kinase mediates Racdependent actin assembly. Curr. Biol. 10:153-156.

17. Wong, K.W., and Isberg, R.R. 2003. Arf6 and phosphoinositol-4-phosphate-5-kinase activities permit bypass of the Rac1 requirement for beta1 integrinmediated bacterial uptake. J. Exp. Med. 198:603-614.

18. Shin, H.W., et al. 2005. An enzymatic cascade of Rab5 effectors regulates phosphoinositide turnover in the endocytic pathway. J. Cell Biol. 170:607-618.

19. Malecz, N., et al. 2000. Synaptojanin 2, a novel Rac1 effector that regulates clathrin-mediated endocytosis. Curr. Biol. 10:1383-1386.

20. Vieira, O.V., et al. 2001. Distinct roles of class and class III phosphatidylinositol 3-kinases in phagosome formation and maturation. J. Cell Biol. 155:19-25.

21. Cox, D., Dale, B.M., Kashiwada, M., Helgason, C.D., and Greenberg, S. 2001. A regulatory role for Src homology 2 domain-containing inositol $5^{\prime}$-phosphatase (SHIP) in phagocytosis mediated by $\mathrm{Fc}$ gamma receptors and complement receptor 3 (alpha(M)beta(2); CD11b/CD18). J. Exp. Med 193:61-71

22. Maresco, D.L., Osborne, J.M., Cooney, D., Coggeshall, K.M., and Anderson, C.L. 1999. The SH2-containing $5^{\prime}$-inositol phosphatase (SHIP) is tyrosine phosphorylated after $\mathrm{Fc}$ gamma receptor clustering in monocytes. J. Immunol. 162:6458-6465.
23. Nakamura, K., Malykhin, A., and Coggeshall, K.M. 2002. The Src homology 2 domain-containing inositol 5-phosphatase negatively regulates Fcgamma receptor-mediated phagocytosis through immunoreceptor tyrosine-based activation motif-bearing phagocytic receptors. Blood. 100:3374-3382.

24. Kamen, L.A., Levinsohn, J., and Swanson, J.A. 2007. Differential association of phosphatidylinositol 3kinase, SHIP-1, and PTEN with forming phagosomes. Mol. Biol. Cell. 18:2463-2472.

25. Fratti, R.A., Backer, J.M., Gruenberg, J., Corvera, S., and Deretic, V. 2001. Role of phosphatidylinositol 3-kinase and Rab5 effectors in phagosomal biogenesis and mycobacterial phagosome maturation arrest. J. Cell Biol. 154:631-644.

26. Ikonomov, O.C., et al. 2002. Functional dissection of lipid and protein kinase signals of PIKfyve reveals the role of PtdIns 3,5-P2 production for endomembrane integrity. J. Biol. Chem. 277:9206-9211.

27. Sbrissa, D., Ikonomov, O.C., and Shisheva, A. 2002. Phosphatidylinositol 3-phosphate-interacting domains in PIKfyve. Binding specificity and role in PIKfyve. Endomenbrane localization. J. Biol. Chem. 277:6073-6079.

28. Vance, J.E., and Steenbergen, R. 2005. Metabolism and functions of phosphatidylserine. Prog. Lipid Res. 44:207-234.

29. Ravichandran, K.S., and Lorenz, U. 2007. Engulfment of apoptotic cells: signals for a good meal. Nat. Rev. Immunol. 7:964-974.

30. Marguet, D., Luciani, M.F., Moynault, A., Williamson, P., and Chimini, G. 1999. Engulfment of apoptotic cells involves the redistribution of membrane phosphatidylserine on phagocyte and prey. Nat. Cell Biol. 1:454-456.

31. Hamon, Y., et al. 2000. ABC1 promotes engulfment of apoptotic cells and transbilayer redistribution of phosphatidylserine. Nat. Cell Biol. 2:399-406.

32. Desjardins, M., et al. 1994. Molecular characterization of phagosomes. J. Biol. Chem. 269:32194-32200.

33. Wang, X., Devaiah, S.P., Zhang, W., and Welti, R. 2006. Signaling functions of phosphatidic acid. Prog. Lipid Res. 45:250-278.

34. Jenkins, G.H., Fisette, P.L., and Anderson, R.A. 1994. Type I phosphatidylinositol 4-phosphate 5-kinase isoforms are specifically stimulated by phosphatidic acid. J. Biol. Chem. 269:11547-11554.

35. Corrotte, M., et al. 2006. Dynamics and function of phospholipase D and phosphatidic acid during phagocytosis. Traffic. 7:365-377.

36. Iyer, S.S., Barton, J.A., Bourgoin, S., and Kusner, D.J. 2004. Phospholipases D1 and D2 coordinately regulate macrophage phagocytosis. J. Immunol. 173:2615-2623.

37. Kay, J.G., Murray, R.Z., Pagan, J.K., and Stow, J.L. 2006. Cytokine secretion via cholesterol-rich lipid raft-associated SNAREs at the phagocytic cup. J. Biol. Chem. 281:11949-11954.

38. Mobius, W., et al. 2003. Recycling compartments and the internal vesicles of multivesicular bodies harbor most of the cholesterol found in the endocytic pathway. Traffic. 4:222-231.

39. Sobo, K., Chevallier, J., Parton, R.G., Gruenberg, J., and van der Goot, F.G. 2007. Diversity of raft-like domains in late endosomes. PLoS ONE. 2:e391.

40. Chen, H., Yang, J., Low, P.S., and Cheng, J.X. 2007. Cholesterol level regulates endosome mobility via Rab proteins. Biophys. J. 94:1508-1520.

41. Li, N., et al. 2003. Monocyte lipid rafts contain proteins implicated in vesicular trafficking and phagosome formation. Proteomics. 3:536-548.

42. Dermine, J.F., et al. 2001. Flotillin-1-enriched lipid raft domains accumulate on maturing phagosomes. J. Biol. Chem. 276:18507-18512.

43. Balla, T. 2005. Inositol-lipid binding motifs: signal integrators through protein-lipid and protein-protein interactions. J. Cell Sci. 118:2093-2104.

44. Lemmon, M.A. 2008. Membrane recognition by phospholipid-binding domains. Nat. Rev. Mol. Cell Biol. 9:99-111.

45. Carlton, J.G., and Cullen, P.J. 2005. Coincidence detection in phosphoinositide signaling. Trends Cell Biol. 15:540-547.

46. Hawkins, P.T., Michell, R.H., and Kirk, C.J. 1984. Analysis of the metabolic turnover of the individual phosphate groups of phosphatidylinositol 4-phosphate and phosphatidylinositol 4,5-bisphosphate. Validation of novel analytical techniques by using 32P-labelled lipids from erythrocytes. Biochem. J. 218:785-793.

47. Lemmon, M.A. 2003. Phosphoinositide recognition domains. Traffic. 4:201-213.

48. Ferguson, K.M., et al. 2000. Structural basis for discrimination of 3-phosphoinositides by pleckstrin homology domains. Mol. Cell. 6:373-384.

49. Lietzke, S.E., et al. 2000. Structural basis of 3-phosphoinositide recognition by pleckstrin homology domains. Mol. Cell. 6:385-394.

50. Misra, S., and Hurley, J.H. 1999. Crystal structure of a phosphatidylinositol 3-phosphate-specific membrane-targeting motif, the FYVE domain of Vps27p. Cell. 97:657-666.

51. Stahelin, R.V., et al. 2002. Phosphatidylinositol 3phosphate induces the membrane penetration of the FYVE domains of Vps27p and Hrs. J. Biol. Chem. 277:26379-26388.

52. Dumas, J.J., et al. 2001. Multivalent endosome targeting by homodimeric EEA1. Mol. Cell. 8:947-958.

53. Kooijman, E.E., et al. 2007. An electrostatic/hydrogen bond switch as the basis for the specific interaction of phosphatidic acid with proteins. J. Biol. Chem. 282:11356-11364.

54. Prehoda, K.E., Scott, J.A., Mullins, R.D., and Lim, W.A. 2000. Integration of multiple signals through cooperative regulation of the N-WASP-Arp2/3 complex. Science. 290:801-806

55. Rohatgi, R., Nollau, P., Ho, H.Y., Kirschner, M.W., and Mayer, B.J. 2001. Nck and phosphatidylinositol 4,5-bisphosphate synergistically activate actin polymerization through the N-WASP-Arp $2 / 3$ pathway. J. Biol. Chem. 276:26448-26452.

56. Schafer, D.A., Jennings, P.B., and Cooper, J.A. 1996. Dynamics of capping protein and actin assembly in vitro: uncapping barbed ends by polyphosphoinositides. J. Cell Biol. 135:169-179.

57. Janmey, P.A., and Stossel, T.P. 1987. Modulation of gelsolin function by phosphatidylinositol 4,5bisphosphate. Nature. 325:362-364.

58. Fukami, K., Endo, T., Imamura, M., and Takenawa, T. 1994. alpha-Actinin and vinculin are PIP2binding proteins involved in signaling by tyrosine kinase. J. Biol. Chem. 269:1518-1522.

59. Sechi, A.S., and Wehland, J. 2000. The actin cytoskeleton and plasma membrane connection: Ptdins $(4,5) \mathrm{P}(2)$ influences cytoskeletal protein activity at the plasma membrane. J. Cell Sci. 113:3685-3695

60. Imai, K., et al. 1999. The pleckstrin homology domain of the Wiskott-Aldrich syndrome protein is involved in the organization of actin cytoskeleton. Clin. Immunol. 92:128-137.

61. Diakonova, M., Bokoch, G., and Swanson, J.A. 2002. Dynamics of cytoskeletal proteins during Fcgamma receptor-mediated phagocytosis in macrophages. Mol. Biol. Cell. 13:402-411.

62. Erwig, L.P., et al. 2006. Differential regulation of phagosome maturation in macrophages and dendritic cells mediated by Rho GTPases and ezrinradixin-moesin (ERM) proteins. Proc. Natl. Acad. Sci.U. S. A. 103:12825-12830.

63. Gu, H., Botelho, R.J., Yu, M., Grinstein, S., and Neel, B.G. 2003. Critical role for scaffolding adapter Gab2 in Fc gamma R-mediated phagocytosis. J. Cell Biol. 161:1151-1161.

64. Oikawa, T., et al. 2004. PtdIns(3,4,5)P3 binding is necessary for WAVE2-induced formation of lamel- 
lipodia. Nat. Cell Biol. 6:420-426.

65. Cox, D., et al. 2002. Myosin X is a downstream effector of PI(3)K during phagocytosis. Nat. Cell Biol. 4:469-477.

66. Falasca, M., et al. 1998. Activation of phospholipase $\mathrm{C}$ gamma by PI 3-kinase-induced $\mathrm{PH}$ domain-mediated membrane targeting. EMBO J. 17:414-422.

67. Cheeseman, K.L., et al. 2006. Targeting of protein kinase C-epsilon during Fcgamma receptordependent phagocytosis requires the epsilonC1B domain and phospholipase C-gamma1. Mol. Biol. Cell. 17:799-813.

68. Larsen, E.C., et al. 2002. A role for PKC-epsilon in Fc gammaR-mediated phagocytosis by RAW 264.7 cells. J. Cell Biol. 159:939-944.

69. Ago, T., et al. 2003. Phosphorylation of $\mathrm{p} 47 \mathrm{phox}$ directs phox homology domain from $\mathrm{SH} 3$ domain toward phosphoinositides, leading to phagocyte NADPH oxidase activation. Proc. Natl. Acad. Sci.U.S. A. 100:4474-4479.

70. Vieira, O.V., et al. 2004. Acquisition of Hrs, an essential component of phagosomal maturation, is impaired by mycobacteria. Mol. Cell. Biol. 24:4593-4604.

71. Bache, K.G., Brech, A., Mehlum, A., and Stenmark, H. 2003. Hrs regulates multivesicular body formation via ESCRT recruitment to endosomes. J. Cell Biol. 162:435-442.

72. Lee, W.L., Kim, M.K., Schreiber, A.D., and Grinstein, S. 2005. Role of ubiquitin and proteasomes in phagosome maturation. Mol. Biol. Cell. 16:2077-2090.

73. Suh, C.I., et al. 2006. The phosphoinositide-binding protein 40 phox activates the NADPH oxidase during FcgammaIIA receptor-induced phagocytosis. J. Exp. Med. 203:1915-1925.

74. Ellson, C., Davidson, K., Anderson, K., Stephens, L.R., and Hawkins, P.T. 2006. PtdIns3P binding to the PX domain of $\mathrm{p} 40$ phox is a physiological signal in NADPH oxidase activation. EMBO J. 25:4468-4478.

75. Yeung, T., et al. 2006. Receptor activation alters inner surface potential during phagocytosis. Science. 313:347-351.

76. Gary, J.D., Wurmser, A.E., Bonangelino, C.J., Weisman, L.S., and Emr, S.D. 1998. Fab1p is essential for PtdIns(3)P 5-kinase activity and the maintenance of vacuolar size and membrane homeostasis. J. Cell Biol. 143:65-79.

77. Odorizzi, G., Babst, M., and Emr, S.D. 1998. Fab1p PtdIns(3)P 5-kinase function essential for protein sorting in the multivesicular body. Cell. 95:847-858.

78. Jefferies, H.B., et al. 2008. A selective PIKfyve inhibitor blocks PtdIns $(3,5) \mathrm{P}(2)$ production and disrupts endomembrane transport and retroviral budding. EMBO Rep. 9:164-170.

79. Ktistakis, N.T., et al. 2003. Phospholipase D1 and potential targets of its hydrolysis product, phosphatidic acid. Biochem. Soc. Trans. 31:94-97.

80. Zimmerberg, J., and Kozlov, M.M. 2006. How proteins produce cellular membrane curvature. Nat. Rev. Mol. Cell Biol. 7:9-19.

81. Verkleij, A.J., De Maagd, R., Leunissen-Bijvelt, J., and De Kruijff, B. 1982. Divalent cations and chlorpromazine can induce non-bilayer structures in phosphatidic acid-containing model membranes. Biochim. Biophys. Acta. 684:255-262.

82. Kooijman, E.E., Chupin, V., de Kruijff, B., and Burger, K.N. 2003. Modulation of membrane curvature by phosphatidic acid and lysophosphatidic acid. Traffic. 4:162-174.

83. Kooijman, E.E., et al. 2005. Spontaneous curvature of phosphatidic acid and lysophosphatidic acid. Biochemistry. 44:2097-2102.

84. Matsuo, H., et al. 2004. Role of LBPA and Alix in multivesicular liposome formation and endosome organization. Science. 303:531-534.

85. McLaughlin, S. 1977. Electrostatic potentials at membrane-solution interfaces. Current Topics in Membranes and Transport. 9:71-144.

86. McLaughlin, S., and Murray, D. 2005. Plasma membrane phosphoinositide organization by protein electrostatics. Nature. 438:605-611.

87. Gambhir, A., et al. 2004. Electrostatic sequestration of PIP2 on phospholipid membranes by basic/aromatic regions of proteins. Biophys. J. 86:2188-2207.

88. Golebiewska, U., et al. 2006. Membrane-bound basic peptides sequester multivalent (PIP2), but not monovalent (PS), acidic lipids. Biophys. $J$. 91:588-599.

89. Heo, W.D., et al. 2006. PI(3,4,5)P3 and PI(4,5)P2 lipids target proteins with polybasic clusters to the plasma membrane. Science. 314:1458-1461.

90. McLaughlin, S., and Aderem, A. 1995. The myristoyl-electrostatic switch: a modulator of reversible protein-membrane interactions. Trends Biochem. Sci. 20:272-276.

91. Yeung, T., et al. 2008. Membrane phosphatidylserine regulates surface charge and protein localization. Science. 319:210-213.

92. Allen, L.H., and Aderem, A. 1995. A role for MARCKS, the alpha isozyme of protein kinase $C$ and myosin I in zymosan phagocytosis by macrophages. J. Exp. Med. 182:829-840.

93. Carballo, E., Pitterle, D.M., Stumpo, D.J., Sperling, R.T., and Blackshear, P.J. 1999. Phagocytic and macropinocytic activity in MARCKS-deficient macrophages and fibroblasts. Am. J. Physiol. 277:C163-C173.

94. Terebiznik, M.R., et al. 2002. Elimination of host cell PtdIns $(4,5) \mathrm{P}(2)$ by bacterial SigD promotes membrane fission during invasion by Salmonella. Nat. Cell Biol. 4:766-773.

95. Hilbi, H. 2006. Modulation of phosphoinositide metabolism by pathogenic bacteria. Cell. Microbiol. 8:1697-1706.

96. Hernandez, L.D., Hueffer, K., Wenk, M.R., and Galan, J.E. 2004. Salmonella modulates vesicular traffic by altering phosphoinositide metabolism. Science. 304:1805-1807.

97. Weber, S.S., Ragaz, C., Reus, K., Nyfeler, Y., and Hilbi, H. 2006. Legionella pneumophila exploits $\mathrm{PI}(4) \mathrm{P}$ to anchor secreted effector proteins to the replicative vacuole. PLoS Pathog. 2:e46.

98. Luo, Z.Q., and Isberg, R.R. 2004. Multiple substrates of the Legionella pneumophila Dot/Icm system identified by interbacterial protein transfer. Proc. Natl. Acad. Sci. U. S. A. 101:841-846.

99. Russell, D.G., Mwandumba, H.C., and Rhoades, E.E. 2002. Mycobacterium and the coat of many lipids. J. Cell Biol. 158:421-426.

100.Vergne, I., Chua, J., and Deretic, V. 2003. Tuberculosis toxin blocking phagosome maturation inhibits a novel Ca2+/calmodulin-PI3K hVPS34 cascade. J. Exp. Med. 198:653-659.

101. Vergne, I., et al. 2005. Mechanism of phagolysosome biogenesis block byviable Mycobacterium tuberculosis. Proc. Natl. Acad. Sci. U. S. A. 102:4033-4038.

102. Kanai, F., et al. 2001. The PX domains of $\mathrm{p} 47$ phox and $\mathrm{p} 40$ phox bind to lipid products of PI(3)K. Nat. Cell Biol. 3:675-678.

103.Tsuboi, S., and Meerloo, J. 2007. Wiskott-Aldrich syndrome protein is a key regulator of the phagocytic cup formation in macrophages. J. Biol. Chem. 282:34194-34203.

104. Ochs, H.D., and Thrasher, A.J. 2006. The WiskottAldrich syndrome.J. Allergy Clin. Immunol. 117:725-738; quiz 739 .
105.Marodi, L., Kaposzta, R., Toth, J., and Laszlo, A. 1995. Impaired microbicidal capacity of mononuclear phagocytes from patients with type I Gaucher disease: partial correction by enzyme replacement therapy. Blood. 86:4645-4649.

106.Liel, Y., et al. 1994. Monocyte dysfunction in patients with Gaucher disease: evidence for interference of glucocerebroside with superoxide generation. Blood. 83:2646-2653.

107. Sillence, D.J., et al. 2002. Glucosylceramide modulates membrane traffic along the endocytic pathway. J. Lipid Res. 43:1837-1845.

108.Trajkovic-Bodennec, S., Bodennec, J., and Futerman, A.H. 2004. Phosphatidylcholine metabolism is altered in a monocyte-derived macrophage model of Gaucher disease but not in lymphocytes. Blood Cells Mol. Dis. 33:77-82.

109. Miyanishi, M., et al. 2007. Identification of Tim4 as a phosphatidylserine receptor. Nature. 450:435-439.

110.Park, D., et al. 2007. BAI1 is an engulfment receptor for apoptotic cells upstream of the ELMO/ Dock180/Rac module. Nature. 450:430-434.

111.Park, S.Y., et al. 2008. Rapid cell corpse clearance by stabilin-2, a membrane phosphatidylserine receptor. Cell Death Differ. 15:192-201.

112.Casciola-Rosen, L., Rosen, A., Petri, M., and Schlissel, M. 1996. Surface blebs on apoptotic cells are sites of enhanced procoagulant activity: implications for coagulation events and antigenic spread in systemic lupus erythematosus. Proc. Natl. Acad. Sci. U. S. A. 93:1624-1629.

113.Herrmann, M., et al. 1998. Impaired phagocytosis of apoptotic cell material by monocyte-derived macrophages from patients with systemic lupus erythematosus. Arthritis Rheum. 41:1241-1250.

114.Licht, R., Dieker, J.W., Jacobs, C.W., Tax, W.J., and Berden, J.H. 2004. Decreased phagocytosis of apoptotic cells in diseased SLE mice. J. Autoimmun. 22:139-145.

115. Dowler, S., et al. 2000. Identification of pleckstrinhomology-domain-containing proteins with novel phosphoinositide-binding specificities. Biochem. J. 351:19-31.

116.Dove, S.K., et al. 2004. Svp1p defines a family of phosphatidylinositol 3,5-bisphosphate effectors. EMBO J. 23:1922-1933.

117. Sciorra, V.A., et al. 2002. Dual role for phosphoinositides in regulation of yeast and mammalian phospholipase D enzymes. J. Cell Biol. 159:1039-1049.

118.Blin, G., et al. 2008. Quantitative analysis of the binding of ezrin to large unilamellar vesicles containing phosphatidylinositol 4,5 bisphosphate. Biophys. J. 94:1021-1033.

119.Ford, M.G., et al. 2001. Simultaneous binding of PtdIns(4,5)P2 and clathrin by AP180 in the nucleation of clathrin lattices on membranes. Science. 291:1051-1055.

120.Ford, M.G., et al. 2002. Curvature of clathrin-coated pits driven by epsin. Nature. 419:361-366.

121.Santagata, S., et al. 2001. G-protein signaling through tubby proteins. Science. 292:2041-2050.

122. Collins, B.M., et al. 2002. Molecular architecture and functional model of the endocytic AP2 complex. Cell. 109:523-535.

123. Baraldi, E., et al. 1999. Structure of the PH domain from Bruton's tyrosine kinase in complex with inositol 1,3,4,5-tetrakisphosphate. Structure. 7:449-460.

124. Newton, A.C., and Johnson, J.E. 1998. Protein kinase C: a paradigm for regulation of protein function by two membrane-targeting modules. Biochim. Biophys. Acta. 1376:155-172. 